\title{
COMPARISON OF TEACHING MACHINE WITH AN OBSERVER IN DETECTION OF ANGINA PECTORIS BY QUESTIONNAIRE
}

\author{
J. S. MILNE AND J. WILLIAMSON
}

\author{
Geriatric Research Unit, Royal Victoria Hospital, Edinburgh 4 and Eastern General Hospital, Edinburgh 6
}

History-taking machines are now in use in health surveys (Mayne, Weksel, and Sholtz, 1968; Slack, Hicks, Reed, and Van Cura, 1966) or their use is suggested (Edwards, 1970). It seems, therefore, worth while to compare history taking by machine with a standard questionnaire administered in the ordinary way.

\section{MeTHOD}

The Geriatric Research Unit in Edinburgh uses a teaching machine (tm 1024 Educational Systems Ltd.) with an attached general purpose datacollecting system (ts 512) for psychological testing. A comparison has been made, using Rose's (1962) questionnaire on angina pectoris, of questions asked by this machine with questions asked in the ordinary way.

The questionnaire was put on coloured film. The first frame displayed 'the pictures you are going to see will ask you questions. You answer each question by pressing RED or BLUE. Each picture will explain which colour you press in your reply. Now press RED'. The capitals represent large red and blue buttons on the teaching machine by means of which dichotomous responses are made. The second frame said 'After this picture the questions begin. Now press BLUE'. These two frames served to familiarize the subject with the machine and to show whether the procedure had been understood.

Succeeding frames carried Rose's questions 1 to 5 exactly as published. Questions 6 and 7 were altered as described below. Question 8, concerning pain other than precordial, and question 9, concerning consultation with a doctor about the pain, were not asked. Each frame offered alternative replies in the form of 'If yes press RED, if no press BLUE'. The machine was programmed to pass steadily through the questionnaire unless the subject pressed a button for an answer which in the published questionnaire would cause the observer to ask no more questions and reject the diagnosis of angina; the machine then displayed a frame saying 'End of Questions'. Question 6 was altered to 'How soon is it relieved?' and was, of course, not asked unless question 5 was answered 'Relieved'. To obtain answers to question 7 concerning the site of the pain, 'Will you show me where it was?', three frames were needed, each of which on a diagram showed a possible pain site and asked 'Do you feel it here?' The film, therefore, as far as possible asks Rose's questions as published but explains on each frame what the alternative answers are.

All persons to whom the questionnaire was administered in the ordinary way were questioned by one observer (J.S.M.) who used the training material supplied by Rose and tested reproducibility before beginning the study (Milne, Hope, and Williamson, 1970).

The subjects examined were men and women aged 63 years and upwards forming a random sample of older people living in a defined area of Edinburgh and taking part in a longitudinal study. This sample has been fully described elsewhere (Milne, Maule, and Williamson, 1971). The investigation described was performed in the second (annual) examination of the longitudinal study. Two hundred and nine men and 244 women took part.

During the first examination all subjects were asked the questions in the ordinary way. One year later subjects were assigned at random to two groups. The first was asked Rose's questions in the ordinary way. The other was questioned by the teaching machine. From the replies can be given the prevalence of angina at the first examination, and the incidence between first and second examinations can be calculated.

Replies fall into three groups: (1) to the ordinary questions, (2) to the machine, and (3) to the ordinary questions when the machine was not in working order or could not be used. This machine was an early model, now obsolete, which easily went out of order and as there was no service engineer in Scotland repairs were inevitably delayed. The machine could not be used on home visits, necessitated by illness, or in blind people. These reasons for not using the machine cannot certainly be said to be random, so although bias from this reason 
TABLE I

PREVALENCE OF ANGINA PECTORIS AT FIRST EXAMIN. ATION (BY ORDINARY QUESTIONNAIRE) DISPLAYED IN GROUPS USED AT SECOND EXAMINATION

\begin{tabular}{|c|c|c|c|c|c|}
\hline \multirow{2}{*}{$\begin{array}{l}\text { Group Used } \\
\text { on Second } \\
\text { Occasion }\end{array}$} & \multicolumn{3}{|c|}{$\begin{array}{c}\text { Angina at First } \\
\text { Examination }\end{array}$} & \multirow[b]{2}{*}{$\mathbf{Z}$} & \multirow[b]{2}{*}{$\mathbf{P}$} \\
\hline & Present & Absent & $\begin{array}{c}\% \\
\text { Present }\end{array}$ & & \\
\hline $\begin{array}{l}\text { Males } \\
\text { Questionnaire } \\
\text { Machine } \\
\text { Machine not } \\
\text { usable }\end{array}$ & $\begin{array}{r}14 \\
6 \\
5\end{array}$ & $\begin{array}{l}91 \\
62 \\
29\end{array}$ & $\left.\begin{array}{c}13.3 \\
8.8 \\
14.7\end{array}\right\}$ & $\begin{array}{l}0.90 \\
0.84\end{array}$ & $\begin{array}{l}>0.05 \\
>0.05\end{array}$ \\
\hline $\begin{array}{l}\text { Females } \\
\text { Questionnaire } \\
\text { Machine } \\
\text { Machine not } \\
\text { usable }\end{array}$ & $\begin{array}{r}15 \\
6 \\
4\end{array}$ & $\begin{array}{r}118 \\
61 \\
35\end{array}$ & $\left.\begin{array}{c}11.4 \\
9.0\end{array}\right\}$ & $\begin{array}{l}0.53 \\
0.22\end{array}$ & $\begin{array}{l}>0.05 \\
>0.05\end{array}$ \\
\hline
\end{tabular}

seems unlikely the results are reported under the three headings.

\section{RESUlts}

The prevalence of angina at the first examination was 25 of $207(12 \cdot 1 \%)$ men and 25 of $239(10.5 \%)$ women. Two men and five women were demented and could not answer the questions. Table I shows the prevalence of angina at the first examination in these men and women classified in the groups in which they were examined on the second occasion.

This shows that the prevalence of angina at the first examination is distributed in similar proportions for each sex in the three groups used at the second examination. All men and women found to have angina at the first examination were removed from the study and Table II shows the incidence of angina between the first and second examinations in those free of angina at the first examination.

The percentages in column 3 show a higher incidence of angina in men and women using the teaching machine. This incidence is significantly different from that found by questions asked in the ordinary

TABLE II

INCIDENCE OF ANGINA PECTORIS BETWEEN FIRST AND SECOND EXAMINATIONS

\begin{tabular}{|c|c|c|c|c|c|}
\hline & \multicolumn{3}{|c|}{ Angina } & \multirow[b]{2}{*}{$\mathbf{Z}$} & \multirow[b]{2}{*}{$\mathbf{P}$} \\
\hline & Present & Absent & Present & & \\
\hline $\begin{array}{l}\text { Males } \\
\text { Questionnaire } \\
\text { Machine } \\
\text { Machine not } \\
\text { usable }\end{array}$ & $\begin{array}{r}5 \\
13 \\
2\end{array}$ & $\begin{array}{l}86 \\
49 \\
27\end{array}$ & $\left.\begin{array}{c}5.5 \\
21.0 \\
6.9\end{array}\right\}$ & $\begin{array}{l}2 \cdot 87 \\
1 \cdot 70\end{array}$ & $\begin{array}{l}<0.01 \\
>0.05\end{array}$ \\
\hline $\begin{array}{l}\text { Females } \\
\text { Questionnaire } \\
\text { Machine } \\
\text { Machine not } \\
\text { usable }\end{array}$ & $\begin{array}{l}2 \\
8 \\
0\end{array}$ & $\begin{array}{r}116 \\
53 \\
35\end{array}$ & $\left.\begin{array}{c}1.7 \\
13 \cdot 1 \\
0\end{array}\right\}$ & $\begin{array}{l}3 \cdot 17 \\
2 \cdot 22\end{array}$ & $\begin{array}{c}<0.01 \\
0.01<\mathrm{P}<0.05\end{array}$ \\
\hline
\end{tabular}

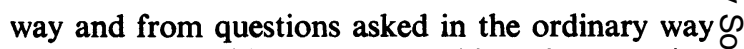
because the machine was not usable. The exception is in comparing 'machine' and 'machine not usable' 3 in men where $Z$ is 1.70 and $P>0.05$. However, the? group of 'machine not usable' consisted of only $29 \overrightarrow{\vec{F}}$ men, so that confidence limits are larger.

\section{Discussion}

The prevalence of angina at the first examination $\frac{\widetilde{\Phi}}{\widetilde{\alpha}}$ in this study is $12.1 \%$ in men and $10.5 \%$ in women. Brown, Davidson, McKeown, and Whitfield (1957) ${ }^{\circ}$ reported a prevalence of $6 \%$ in men of the seventh $\vec{O}$ decade. Droller and Pemberton (1953), in a random $\overrightarrow{-}$ sample of 476 elderly people, reported disabling ${ }_{\sigma}$ angina in $6.5 \%$ of men and women, with a larger percentage of milder symptoms. Reid, Holland, $\stackrel{\circ}{-}$ Humerfelt, and Rose (1966), in postal workers agedin 40 to 59 years, reported a prevalence of $4 \%$. Roseiv (1968) found a prevalence at the initial examination $\vec{\circ}$ of $3.8 \%$ in men aged 35 to 59 . Taking account of the increasing prevalence of angina with age, it? seems that the prevalence at the first examinationin the present study is consistent with other reported studies.

The present study reports an annual incidence of $\overrightarrow{0}$ angina in men of $5.5 \%$ detected by questionnaie,,of $6.9 \%$ by questionnaire (machine not usablet. and of $21 \%$ by teaching machine. The annutio incidence reported by Rose $(1968)$ in men aged $\overrightarrow{35}$ to 59 varied from 1.0 to $3.6 \%$, and that reported by Paul et al. (1963) in men aged 40 to 45 was $0.5 \%$. Stamler et al. (1960) reported a $1.5 \%$ incidence of $\overrightarrow{\vec{A}}$ all coronary heart disease in men aged 50 to $59 . \frac{3}{3}$ Chapman et al. (1957) found an incidence of all coronary heart disease of $2.9 \%$ in men aged 55 to 70 .ह The present study has a one-year incidence of angina in women of $1.7 \%$ detected by questionnaire and $13.1 \%$ by teaching machine. These figures suggest:that in both men and women use of the teaching 3 . machine led to a falsely high incidence of anginas between the first and second examinations. Wes consider that the fault is in the machine estimateo rather than in that of the oral questionnaire because the questionnaire has been carefully validatedo (Rose, 1962; Rose and Blackburn, 1968) and in the present study care was taken to use the orater questionnaire in the way advised by Rose.

All through the questionnaire on film each framen offers alternative answers, with 'yes' or other positive equivalent always the upper alternative. A subjeck who becomes 'set' on this button will go througit the whole questionnaire and emerge labelled anginas positive. The high false positive results from the teaching machine may therefore be an example of a phenomenon known to psychologists as response्D 
set. Eysenck (1970), discussing scales of authoritarianism, says 'many subjects respond in a stereotyped manner regardless of the content of the question asked. Thus an acquiescent person might tend to reply with "yes" to all questions in a questionnaire regardless of their content. As all the items in the authoritarian scale are worded in such a way that "yes" answers are in the authoritarian direction, it is not impossible that the test might measure acquiescence rather than authoritarianism'. The principle here described in the particular case of authoritarianism applies in general to all similarly constructed questionnaires. Vernon (1964), discussing validity, says 'the common element running through a set of intercorrelated tests may be a response set rather than the presumed trait'.

A fundamental difference between Rose's questions asked in the ordinary way and by the teaching machine is that while all 'yes' (or equivalent to 'yes') answers on the machine are in the angina direction, only the first three of Rose's questions asked in the ordinary way have 'yes' in the angina direction. The other questions asked in the ordinary way invite a reply which cannot be literally 'yes' or 'no' and the possible replies are not indicated by the questions. As an example, 'If you stand still what happens to it?' The machine says 'If RELIEVED press RED. If NOT RELIEVED press BLUE', and a person set on the red button still replies in the angina direction. The question asked in the ordinary way does not indicate any answer as being in the angina direction and the subject has to think of his reply. Response set seems less likely with questions asked in the ordinary way. It is easy to see why Rose insists that the questions should be asked exactly as published without changing a word.

The importance of response set at a time when investigators are turning to visual display to ask questions can be shown from the literature. Slack et al. (1966), in the Multiphasic Checkup of the Permanente Medical Group, displayed a series of questions on a screen beneath which the possible responses 'yes', 'no', 'don't know', and 'don't understand' were listed one above the other numbered 1 to 4 , and the subject answered by pressing one of four numbered keys. Answers were fed into a computer. The authors reported that in 50 subjects investigated for a history of allergy by this method and separately investigated by a physician in the ordinary way, computer and physician agreed in respect of 13 people. The computer obtained a positive history in 22 people not found positive by the physician. In this system the history taking is flexible in that 'yes' leads to a qualifying question and 'no' stops the particular line of questions and leads to a further general question. These results resemble those reported in the present study.

Also, in the Permanente Medical Group, Collen et al. (1964) described self-administered questioning by sorting prepunched I.B.M. cards into a divided letter box with middle section 'yes' and bottom section 'no'. Mayne et al. (1968), in the Mayo Clinic, collected data before interview by a physician using a display terminal on which the patient recorded his responses by means of an electronic light pen, but although the system was flexible with 'branching' techniques of questioning, all 'firstlevel' questions were of a fixed-choice type. Difficulty may arise even with self-administered questionnaires. Brodman and van Woerkom (1966), using a Medical Data Index based on the Cornell Medical Index (before examination by a physician), asked patients to circle 'yes' or 'no' after each question. Physicians diagnosed 2.9 diseases per patient and the Index 3.8 diseases per patient. Physicians, commenting on the $\mathbf{0 . 9}$ disease excess of the Index, said that in 0.4 no information was available as to whether the disease was present and that in 0.5 the disease was known not to be present. All these symptoms offer alternative answers apparently with the order of presentation fixed. Edwards (1970), in a paper describing a carefully worked out flow diagram to investigate dysphagia, with 'yes'-'no' responses, mentioned a teaching machine on-line to a computer as a means of using the system but was careful to warn that an experienced doctor is needed to interpret the results. Concerning the teaching machine he noted the 'significant proportion of patients who will not answer the question asked even if they can read it', a comment which confirms the authors' experience among older people.

When the questionnaire for the present study was put on film, the authors were unaware of the dangers of using a technique where 'yes' was in a constant position. From the literature it appears that however well known response set may be to psychologists, it is less well recognized by physicians, in which case the present study offers a warning. It would be possible to programme the machine so that the blue button was used as 'yes' rather than 'no' in some of the frames. Further study would be needed to determine whether this improved the results or, in old people, caused confusion.

\section{CONCLUSION}

While histories collected by machines and processed by computers may eventually help the doctor to save time, the present authors' experience among 
older people and a brief survey of the literature suggest that care is needed in validating these methods before using them.

\section{SUMmary}

Results are presented comparing the incidence of angina pectoris determined by Rose's questionnaire used by one observer with that determined by a teaching machine using the same questions on film. The machine produces a falsely high incidence, due probably to a cause well recognized by psychologists. Evidence is presented from the literature to show that this may affect results in surveys using history-taking machines.

The authors wish to thank Professor G. A. Rose for permission to put his angina questionnaire on film and Mrs. D. Gilchrist for providing information from the psychological literature.

This work was supported by a grant from the Secretary of State for Scotland via the Advisory Committee on Medical Research.

\section{REFERENCES}

Brodman, K., and van Woerkom, A. J. (1966). Computer-aided diagnostic screening for 100 common diseases. J. Amer. med. Ass., 197, 901.

Brown, R. G., Davidson, L. A. G., McKeown, T., and Whitfield, A. G. W. (1957). Coronary artery disease. Influences affecting its incidence in males in the seventh decade. Lancet, 2, 1073.

Chapman, J. M., Goerke, L. S., Dixon, W., Loveland, D. B., and Prillips, E. (1957). IV The clinical status of a population group in Los Angeles under observation for two to threc years. Amer. J. publ. Hlth, 47, No. 4, Pt. II, 33.

Collen, M. F., Rubin, L., Neyman, J., Dantzig, G. B., Baer, R. M., and Siegelaub, A. B. (1964). Automated multiphasic screening and diagnosis. Amer. $J$. publ. Hlth, 54, 741.
Droller, H., and Pemberton, J. (1953). Cardiovascular $\mathscr{C}$ disease in a random sample of elderly people. Brit. Heart J., 15, 199.

EDWARDS, D. A. W. (1970). Flow charts, diagnostic keys ? and algorithms in the diagnosis of dysphagia. Scot. $\Rightarrow$ med. J., 15, 378.

EYSENCK, H. J. (1970). The Structure of Human Personality, 3rd. ed. Methuen, London.

Mayne, J. G., Weksel, W., and Sholtz, P. N. (1968). Towards automating the medical history. Mayo Clin. Proc., 43, 1.

Milne, J. S., Hope, K., and Williamson, J. (1970). Variability in replies to a questionnaire on symptoms $\vec{O}$ of physical illness. J. chron. Dis., 22, 805.

- Maule, M. M., and Williamson, J. (1971). Method of sampling in a study of older people with a comparison of respondents and nonrespondents. Brit. J.prev. soc. Med., 25, 37.

Paul, O., Lepper, M. H., Phelan, W. H., Dupertuis, ज̂ G. W., MacMillan, A., McKean, H., and Park, H. ? (1963). A longitudinal study of coronary heart disease. $\vec{\circ}$ Circulation, 28, 20.

Reid, D. D., Holland, W. W., Humerfelt, S., and $\stackrel{\circ}{5}$ Rose, G. (1966). A cardiovascular survey of British $\rightarrow$ postal workers. Lancet, i, 614.

Rose, G. A. (1962). The diagnosis of ischaemic heart pain and intermittent claudication in field surveys. $\vec{\varphi}$ Bull. Wld Hlith Org., 27, 645.

(1968). Variability of angina. Brit. J. prev. so Med., 22, 12.

- and Blackburn, H. (1968). Cardiovascular surve methods. W.H.O., Geneva.

Slack, W. V., Hicks, G. P., Reed, C. E., and Van CURA, L. J. (1966). A computer-based medical history system. New Engl. med. J., 274, 194.

Stamler, J., Lindberg, H. A., Berkson, D. M., Shaffer, A., Miller, W., and Poindexter, A. (1960). Prevalence and incidence of coronary heart disease in strata of the labour force of a Chicago industrial corporation. J. chron., Dis., 11, 405.

Vernon, P. E. (1964). Personality Assessment. Methuen, London. 